University of Nebraska - Lincoln

DigitalCommons@University of Nebraska - Lincoln

Faculty Publications, Department of Psychology

Psychology, Department of

2005

Developmental Stability and Change in Self-Regulation From

Childhood to Adolescence

\author{
Marcela Raffaelli \\ University of Nebraska-Lincoln, mraffaelli1@unl.edu \\ Lisa Crockett \\ University of Nebraska-Lincoln, ecrockett1@unl.edu \\ Yuh-Ling Shen \\ University of Nebraska-Lincoln
}

Follow this and additional works at: https://digitalcommons.unl.edu/psychfacpub

Part of the Psychiatry and Psychology Commons

Raffaelli, Marcela; Crockett, Lisa; and Shen, Yuh-Ling, "Developmental Stability and Change in SelfRegulation From Childhood to Adolescence" (2005). Faculty Publications, Department of Psychology. 351.

https://digitalcommons.unl.edu/psychfacpub/351

This Article is brought to you for free and open access by the Psychology, Department of at DigitalCommons@University of Nebraska - Lincoln. It has been accepted for inclusion in Faculty Publications, Department of Psychology by an authorized administrator of DigitalCommons@University of Nebraska - Lincoln. 


\title{
Developmental Stability and Change in Self-Regulation From Childhood to Adolescence
}

\author{
MARCELA RAFFAELLI \\ Department of Psychology and Institute for Ethnic Studies \\ University of Nebraska-Lincoln \\ LISA J. CROCKETT \\ YUH-LING SHEN \\ Department of Psychology \\ University of Nebraska-Lincoln
}

\begin{abstract}
The authors examined the developmental course of self-regulation in a cohort of children from the National Longitudinal Survey of Youth. The longitudinal sample included 646 children (48\% girls; 52\% boys; 36.2\% Black, 23.4\% Hispanic, $40.4 \%$ White) who were 4 to 5 years old in 1986 and who were followed up at ages 8 to 9 and ages 12 to 13. Levels of self-regulation (assessed with 12 maternal-report items that measured regulation of affect, behavior, attention) increased from early childhood (when sample children were 4 or 5 years old) to middle childhood (ages 8 or 9), but not from middle childhood to early adolescence (ages 12 or 13). Girls exhibited significantly higher levels of self-regulation than did boys at all 3 time points. Individual differences in selfregulation were fairly stable across the 8 -year span $(r s=.47$ to .50$)$. Comparisons of 1 -, 2-, and 3-factor models suggested that the different aspects of self-regulation are highly interrelated, and support adoption of a single-factor model for both genders. The authors discuss implications of these findings for theory and intervention.
\end{abstract}

Key words: individual differences, longitudinal research, self-regulation development

DURING THE FIRST DECADE OF LIFE, a dramatic transformation occurs as infants, who are largely dependent on others, become children who can monitor their own behavior, direct their attention, and regulate their emotional states. These transformations, as well as their origins and consequences, have been the focus of a large body of developmental research. Scholars are now attempting to integrate these often disparate findings by focusing on self-regulation (or closely related constructs) as an individual-level characteristic with enduring implications for longterm functioning. We define self-regulation as the internally-directed capacity to regulate affect, attention, and behavior to respond effectively to both internal and 
environmental demands. This definition draws on previous work by researchers who have focused primarily on emotion-related regulation in infancy and early childhood (e.g., Eisenberg et al., 1995; Graziano \& Tobin, 2000) as well as examinations of additional aspects of self-regulation in later childhood and beyond (e.g., Abraham \& Sheeran, 2000; Barkley, 1997; Baumeister, Leith, Muraven, \& Bratslavsky, 1998). Our approach builds on scholarship that views self-regulation as an interrelated set of capacities that contribute to competent functioning over the life span (Bronson, 2000; Committee on Integrating the Science of Early Childhood Development, 2000; Diaz \& Fruhauf, 1991; Posner \& Rothbart, 2000; Zimmerman, 2000).

Theoretical models and empirical findings indicate that self-regulatory capacities emerge and stabilize during childhood and adolescence (Bronson, 2000; Demetriou, 2000; Kopp, 1982). However, a number of issues remain to be addressed. First, because most scholars have focused on the first 6 to 8 years of life, relatively little is known about age-related development in self-regulation after middle childhood. Second, much of the research has involved cross-sectional studies or longitudinal studies that are limited in duration, sample size, or measures. Few large-scale longitudinal studies have followed the same children for extended periods of time, and most studies use different measures of self-regulation at different ages. As a result, the developmental picture is fragmented and sometimes inconsistent. Third, the structure of self-regulation at different ages has not been examined. Several dimensions of self-regulation have been identified. Some scholars have addressed emotional regulation, others behavioral regulation, and still others attentional regulation. It is not clear how these different components are interrelated at different ages. In the present study, we used a large-scale longitudinal sample drawn from the National Longitudinal Survey of Youth (NLSY) to examine the development of children's self-regulation from early childhood through early adolescence.

\section{Developmental Course of Self-Regulation}

Developmental models (e.g., Demetriou, 2000; Diaz \& Fruhauf, 1991; Kopp, 1982) have addressed the changing self-regulatory tasks confronted at different ages. For example, infants initially face challenges associated with physiological self-regulation (e.g., coordinating sleep and wake cycles) and early modulation of emotions (e.g., self-soothing); toddlers confront issues of compliance and

This research was funded by a grant to Marcela Raffaelli and Lisa J. Crockett from the National Institute of Mental Health (RO1-MH62977). Myesha Albert, Brett Avila, Jennifer Bowers, Rebecca Colman, Jenenne Geske, Sam Hardy, Kristin Moilanen, Andy Peytchev, and Devan Starks provided research assistance.

Address correspondence to Marcela Raffaelli, Department of Psychology and Institute for Ethnic Studies, 238 Burnett Hall, University of Nebraska, Lincoln, NE 68588-0308; mraffaelli1@unl.edu (e-mail). 
behavioral self-control; and preschool-aged children begin to delay gratification. There is a large body of literature on self-regulatory processes during the first 6 years of life (for reviews, see Bronson, 2000; Committee on Integrating the Science of Early Childhood Development, 2000; Gottfredson \& Hirschi, 1990; Grolnick \& Farkas, 2002). Those studies indicate that by the time children enter kindergarten (age 5 to 6 years in the United States) they are "increasingly capable of true internal self-regulation" (Bronson, p. 71). However, self-regulatory skills are likely to continue to develop throughout childhood because many of the cognitive capacities that have been linked to effective adult self-regulation (e.g., long-term planning, goal setting) do not fully mature until later childhood or adolescence (Bronson; Demetriou).

There is evidence that self-regulation continues to develop throughout childhood and into the second decade of life, although fewer scholars have examined these age periods. In their review of research on the development of emotion regulation, Murphy, Eisenberg, Fabes, Shepard, and Guthrie (1999) concluded that regulatory capacities increase into preadolescence. Based on a 6-year longitudinal study of 94 children initially aged 4 to 6 years, these researchers reported that three aspects of regulation showed age-related change (attention shifting and inhibitory control increased over time, impulsivity decreased), whereas two other aspects (attention focusing, behavioral regulation) did not change. Cross-sectional studies of behavioral regulation also have indicated increases in self-regulation across middle childhood and early adolescence. Levine and colleagues (1991, cited in Barkley, 1997) reported significant age-related declines between ages 7 to 8 years and 9 to 12 years in impulsive errors on a behavioral assessment of inhibitory control. Similarly, delay-of-gratification studies with children, adolescents, young adults, and older adults have revealed age-related increases in how likely individuals are to choose a larger delayed reward compared with a smaller immediate reward (Green, Fry, \& Myerson, 1994). Finally, a cross-sectional study of children aged 6 to 12 years indicated that older children exhibit more effective self-regulatory strategies owing to cognitive advances such as abstract thinking (Mischel, Shoda, \& Rodriguez, 1989) and planning ability (see Barkley, for a review).

Taken together, these findings support the continued development of selfregulation after early childhood. In the present study, we built on that literature by examining the development of self-regulation from childhood into adolescence using a large longitudinal sample. In addition to examining developmental changes in the level of self-regulation, we addressed three issues: (a) the structure of selfregulation at different ages; (b) the stability of individual differences; and (c) the gender differences in structure, level, and stability of self-regulation.

\section{Structure of Self-Regulation}

Self-regulation has been conceptualized in diverse ways in the developmental literature, reflecting implicit or explicit assumptions about the construct and its 
components. A full review of the theoretical literature on self-regulation is beyond the scope of this paper; however, at least three models can be identified. One model depicts the regulation of emotion, attention, and behavior as distinct (but perhaps related) processes. In keeping with this framework, some researchers have examined dimensions of self-regulation largely in isolation from each other. Examples include work on behavioral regulation, such as delay of gratification and impulse control (e.g., Feldman \& Brown, 1993; Mischel et al., 1989), and research on emotional regulation (see Gross, 1999, for a review).

A second approach focuses on the dimensions of emotionality and regulation as theoretically distinct constructs. This model is prominent in early childhood studies and has been heavily influenced by models of temperament and emotion regulation (e.g., Derryberry \& Rothbart, 1988; Eisenberg et al., 1995; Eisenberg et al., 1997; Murphy et al., 1999). Scholars working within this tradition typically conceptualize emotionality and regulation as separate domains. However, empirical studies have indicated that emotionality and regulation covary, with correlations between measures of these constructs running as high as .50 to .60 (Eisenberg et al., 1993; Lengua, West, \& Sandler, 1998), and factor analysis sometimes yielding one global factor (e.g., Eisenberg et al., 1995). These findings support the notion that, although distinguishable conceptually, the dimensions of self-regulation may be highly related empirically.

On the basis of these and related findings, a third model posits that selfregulatory processes are integrated and not readily distinguishable in daily experience. Conceptually, it appears likely that the dimensions of self-regulation are interrelated in complex ways and that multiple dimensions come into play in responding to everyday childhood challenges (Bronson, 2000; Committee on Integrating the Science of Early Childhood Development, 2000; Diamond \& Aspinwall, 2003; Fox \& Calkins, 2003; Kopp, 1982). For example, to comply with parental requests not to touch an attractive toy, children must be able to calm themselves despite the tension between their own desires and those of their parents (emotion regulation), redirect their attention to avoid temptation (attention regulation), and if necessary use behavioral strategies to avoid touching the toy such as sitting on their hands or turning away from the toy (behavior regulation). Little research exists on the interrelations of different aspects of self-regulation (aside from the research on emotionality and regulation that we previously described). In one study of 24-month-old children, researchers reported significant linkages between physiological regulation and both emotional and behavioral regulation, but not between behavioral and emotional regulation (Calkins, Smith, Gill, \& Johnson, 1998). We did not find similar work conducted with older children, and researchers have not examined whether specific components of selfregulation are especially salient at particular developmental periods. In the present study, we examined the structure of self-regulation and the distinctiveness of individual components by examining the underlying factor structure of self-regulation at three developmental periods. 


\section{Stability of Individual Differences}

Much of the research on the developmental course of self-regulation involves cross-sectional or short-term longitudinal studies (Bronson, 2000; Committee on Integrating the Science of Early Childhood Development, 2000; Grolnick \& Farkas, 2002). Therefore, researchers have not been able to examine the long-term stability of individual differences in self-regulation-that is, the extent to which children maintain their relative ranking among peers over time. In one of the few longitudinal studies, Murphy and colleagues (1999) found considerable evidence of stability in a group of children studied when they were 6 to 8 years old and followed longitudinally. For example, correlations between baseline and follow-up parent reports of attention focusing, inhibitory control, and behavioral self-regulation across two assessment points 4 years apart (from the baseline assessment to when children were 10 to 12 years old), were $.67, .63$, and .41 , respectively.

Results of studies examining early predictors of adolescent outcomes also provide a basis for hypothesizing that individual differences in self-regulation persist over time. In one study, children's ability to delay gratification at age 4 years was linked to parent ratings of multiple indicators of competence more then 10 years later, including academic and social competence, resistance to temptation, planfulness, and coping (Mischel et al., 1989). Because these outcomes are conceptually linked to self-regulation, the findings are consistent with the existence of stable individual differences in underlying self-regulatory abilities. Similarly, indicators of early childhood lack of control (including short attention span, emotional liability, restlessness) have been linked to adolescent externalizing behavior (Caspi, Henry, McGee, Moffitt, \& Silva, 1995). Such patterns could reflect stable individual differences in self-regulation, with young children who are high in self-regulatory capacities relative to their peers continuing to show comparatively high levels of self-regulation during middle childhood and adolescence. In the present study, we examined individual differences in self-regulation across 8 years (from ages 4 to 5 years until ages 12 to 13 years).

\section{Gender Differences in Self-Regulation}

On the basis of previous scholarship, we expected gender differences in levels of self-regulation. In one study (Kochanska, Murray, \& Harlan, 2000), girls scored higher than did boys at both 22 and 33 months of age on multiple measures of effortful control, indexed by behavioral tasks (e.g., ability to delay gratification, slow motor activity, direct attention). Parents who participated in the study by Murphy et al. (1999) rated girls significantly higher than they rated boys on three measures of self-regulation (attention shifting, behavioral regulation, inhibition control). On the basis of a research review that examined behavioral, attentional, and emotional aspects of regulation, Stifter and Spinrad (2002) concluded that boys tended to be 
poorer self-regulators than did girls. Those results provided a basis for examining gender differences in the development of self-regulation.

\section{Overview of the Present Study}

In this study, we investigated the development of self-regulation from early childhood to adolescence by examining issues of structure, stability, and change; and by comparing developmental patterns for girls and boys. Our analysis benefited from use of a large-scale dataset, the NLSY, which allowed us to address several limitations of previous research, including small samples and inconsistent measurement. Most longitudinal studies have involved different measures of selfregulatory capacities over time, which limited the opportunity to assess developmental patterns. The study by Murphy et al. (1999) is an exception in that it included substantially similar measures of self-regulatory capacities at different ages; however, the sample size limited the conclusions that could be drawn. In several other longitudinal studies (e.g., Caspi et al., 1995; Mischel et al., 1989), childhood self-regulatory capacities were linked to adolescent behaviors associated with self-control (or its absence), but adolescent self-regulation was not directly assessed. In the present analysis, we measured self-regulation consistently across three time points-from early childhood to early adolescence (ages 4 to 5 years, 8 to 9 years, 12 to 13 years).

We examined four research questions:

1. What is the structure of self-regulation? We examined three models derived from developmental theory and empirical research: (a) a tripartite model that incorporated discrete dimensions of self-regulation (i.e., emotion, attention, behavior); (b) a two-factor model that reflected the domains of emotionality and regulation; and (c) a global, unidimensional model. By comparing the resulting models within and across time points, we were able to evaluate the plausibility of these three models and examine the longitudinal stability of the factor structure of self-regulation.

2. Do self-regulatory capacities increase over time? Many of the neural underpinnings and cognitive capacities that have been linked to effective self-regulation do not fully mature until late childhood or adolescence (Demetriou, 2000). Thus, we predicted that mean levels of self-regulation would increase with age, reflecting normative developmental changes. However, on the basis of past work that suggested that self-regulatory capacities are largely in place by middle childhood (for reviews, see Barkley, 1997; Bronson, 2000; Gottfredson \& Hirschi, 1990), we expected more change between early childhood and middle childhood than between middle childhood and early adolescence.

3. Do individual differences in self-regulation stabilize during childhood? On the basis of the handful of long-term studies that have examined children's functioning in relation to self-regulation (e.g., Caspi et al., 1995; Eisenberg et al., 1995, 
1997; Mischel et al., 1989; Murphy et al., 1999), we predicted that individual differences in self-regulation would be relatively stable over time, especially after middle childhood, when self-regulatory processes are well established.

4. Are there gender differences in the development of self-regulation? On the basis of past developmental research, we hypothesized that girls and boys would show different patterns of self-regulation development, such that girls would show higher levels than would boys and perhaps reach mature levels at younger ages.

\section{Method}

\section{Sample and Procedures}

The analytic sample consisted of children of participants in the NLSY. The NLSY began in 1979 with a national sample of 12,686 young adults aged 14 to 21 (Zagorsky \& White, 1999). The researchers initially over-sampled Blacks, Hispanics, and Whites with low socioeconomic status (SES) to provide adequate representation; however, they dropped the low SES White oversample from the study after the 1990 interview round (Zagorsky \& White, p. 6). Starting in 1986, children of female participants were added and have been assessed at 2-year intervals since that time. As part of a larger longitudinal investigation of self-regulation, we identified a cohort of children aged 4 to 5 years in 1986. In cases where multiple siblings participated in the study, we randomly selected one sibling for inclusion. The resulting cohort consisted of 855 children (37\% Black, 24\% Hispanic, 39\% White).

In the present analysis, we utilized data from three waves: 1986 (Time 1), 1990 (Time 2), and 1994 (Time 3), when sample children were 4 to 5, 8 to 9 , and 12 to 13 years old, respectively. To use the most representative sample possible, we conducted analyses that examined the factor structure of self-regulation with all available participants at each time point (Time 1, $n=838$; Time 2, $n=736$; Time 3, $n=693$ ). In our longitudinal analyses, we included children who were present at all three waves and had self-regulation data at each time point $(n=646)$. The longitudinal sample included $75 \%$ of the original cohort and was evenly divided by gender (48\% girls, $52 \%$ boys); the ethnic and racial breakdown was comparable to the Time 1 cohort, and consisted of Blacks (36.2\%), Hispanics (23.4\%) and Whites $(40.4 \%)$. We conducted analyses to compare the 646 children in the longitudinal sample with the 209 who were either lost to follow up ( $n=165$ ) or excluded because of missing data $(n=44)$ at either Time 2 or Time 3 . The retained and excluded groups did not differ in gender, racial/ethnic distribution, or Time 1 levels of selfregulation.

\section{Measures}

Gender and racelethnicity. At Time 1, mothers reported their child's gender and race/ethnicity, which was coded as Hispanic, Black, or non-Hispanic and non- 
Black. The latter group was primarily White and we referred to this group as White.

Self-regulation. The self-regulation measure consisted of 12 items from the 28item Behavior Problems Index (BPI; Peterson \& Zill, 1986; Zill, 1990). At each time point, mothers reported how well the items described their child's behavior during the last 3 months, using a three-point scale from often true (1) to not true (3). Consistent with the conceptualization of self-regulation as a multidimensional construct, we selected items reflecting regulation of affect, attention, and behavior. Affect items tapped into both emotional volatility (e.g., "He/she has sudden changes in mood or feeling") and intensity of expressed emotion (e.g., "He/she has a very strong temper and loses it easily"). "He/she has difficulty concentrating; cannot pay attention for long" was an indicator of attention regulation, and "He/she is restless or overly active, cannot sit still" was an indicator of behavior regulation. Other indicators were attention regulation (e.g., "He/she has difficulty concentrating; cannot pay attention for long") and behavior regulation (e.g., "He/she is restless or overly active, cannot sit still").

Given the source of the self-regulation items, several steps were taken to make sure that the measure was not simply reflecting behavior problems. First, to ensure that the self-regulation measure did not overlap with pre-existing externalizing problems, we excluded items indicative of antisocial behavior (e.g., bullying, lying, breaking things deliberately), peer problems (e.g., trouble getting along with others, not liked) and oppositional behavior (e.g., disobedience, arguing). Second, we compared the 12 items to those used in previous developmental research. Similar items have been used by researchers examining emotionality and self-regulation (e.g., Eisenberg et al., 1993, 1995; Lengua, 2002), behavioral self-restraint (Feldman \& Brown, 1993), and impulsiveness (Eysenck \& Eysenck, 1978). The full list of items used in the self-regulation measure is provided in the appendix.

For analyses involving global self-regulation, we computed a total score by averaging across the items for each year-higher scores corresponded to higher levels of self-regulation. Alphas were .79, .84, and .84 at Time 1, Time 2, and Time 3, respectively. To receive a total self-regulation score, participants had to have at least $75 \%$ of the items within each of the three areas of affect, attention, and behavior at a particular time point. For cases meeting this criterion, we computed average scores based on the valid items.

\section{Analysis Plan}

We addressed the first research question (the structure of self-regulation) by conducting confirmatory factor analyses specifying one-, two-, and three-factor models at each time point using LISREL ${ }^{\circledR} 8.5$ (Jöreskog \& Sörbom, 1998). In addition to examining this question in our main cohort, we capitalized on the structure of the NLSY and replicated these analyses in a second cohort to evaluate the robustness of the findings. The children in the replication sample were 
ages 4 to 5 years in 1988 (Time 1), 8 to 9 years in 1992 (Time 2), and 12 to 13 years in 1996 (Time 3). Similar to the main cohort, the replication sample $(n=$ 890 at Time 1 ) was evenly divided by gender ( $51 \%$ girls, $49 \%$ boys). The race/ethnicity breakdown was $43 \%$ White, $35 \%$ Black, and $22 \%$ Hispanic.

We examined the second research question (age-related changes in selfregulation) by using repeated measures analysis of variance (ANOVA) with global self-regulation as the dependent variable, time point as a repeated factor, and gender as a between-groups factor. We examined the third research question (stability of individual differences in self-regulation) by computing correlation coefficients across the three time points, for the overall sample and within gender. We examined gender effects in each set of analyses to address the fourth research question with regard to gender differences in the development of self-regulation.

\section{Results}

\section{Structure of Self-Regulation}

Our goal in the first set of analyses was to determine whether self-regulation is more appropriately conceptualized as a multifaceted construct or as an integrated psychological construct. First, we examined the distinctiveness of the conceptual domains of self-regulation - affect, attention, and behavior-by comparing one-, two-, and three-factor models of self-regulation using confirmatory factor analysis (CFA). The three-factor model reflected the three components of affect, attention, and behavior; the two-factor model corresponded to the distinction between emotionality and regulation prominent in the literature on early childhood; and the one-factor model specified that the different aspects of selfregulation are so tightly interwoven that they are indistinguishable in everyday behavior. Because the chi-square statistic is sensitive to sample size (Kelloway, 1998; Kline, 1998), models were evaluated using several different fit indexes. The Goodness-of-Fit Index (GFI) is an absolute fit index that indicates the proportion of the observed covariances explained by the model-implied covariances. The Comparative-Fit Index (CFI) and Non-Normed-Fit Index (NNFI) are relative fit indexes measuring the improvement of the specified model over a null model where all covariances are assumed to be zero; the NNFI is adjusted for the model degrees of freedom. It is generally accepted that GFI, CFI, and NNFI values greater than .90 indicate adequate fit (Hu \& Bentler, 1995; Kelloway; Kline; Maruyama, 1998). Finally, the Root Mean Squared Error of Approximation $(R M S E A)$ is an analysis of residuals; the criterion for good fit ranges from $<.05$ to <.10 (Jöreskog \& Sörbom, 1998; Kelloway; Maruyama). Results for the three models at each of the three time points are displayed in Table 1.

Figure 1 depicts the one-factor model and loadings of the observed variables at the three time points. The standardized coefficients indicated fairly 


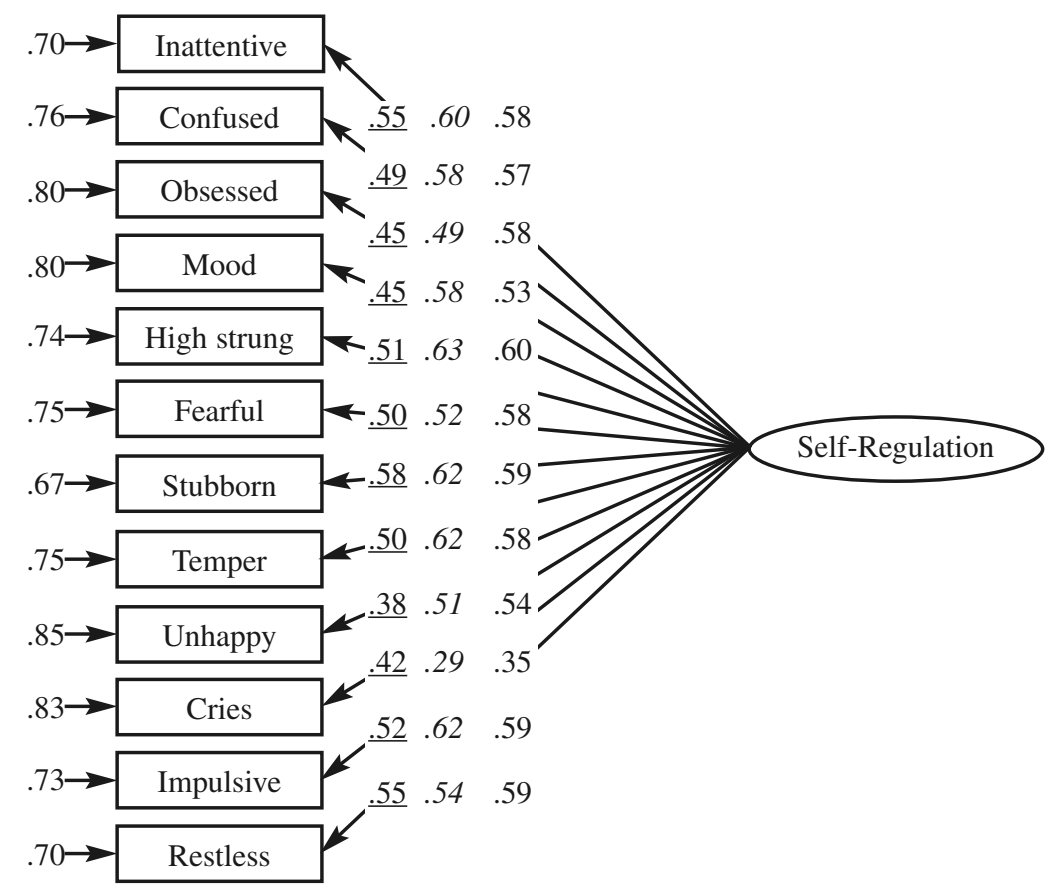

FIGURE 1. Confirmatory factor analysis results of 1-factor model of selfregulation. All coefficients are standardized. Error variances of indicators are from 1986. Underlined numbers are Time 1 coefficients; italicized numbers are Time 2 coefficients; and regular numbers are Time 3 coefficients.

good convergent validity, with most of the loadings close to .50 or higher (all were significant at $p<.001)$. At Time 1 the chi-square value for the one-factor model was large and significant; however, the other fit indexes suggested a good fit (GFI, CFI, and NNFI ranged from .94 to .96; RMSEA = .06). Statistics for the one-factor model at Time 2 and Time 3 revealed a somewhat poorer fit, although the fit indexes were all within acceptable ranges (see Table 1).

The two-factor model (emotionality, regulation) also provided a good fit to the data. The standardized coefficients indicated fairly good convergent validity, with most of the loadings close to .50 or higher (all significant at $p<.001$; results not shown). Specifically, factor loadings for emotionality ( 7 items: mood, high strung, fearful, stubborn, temper, unhappy, cries) ranged from .40 to .60 at Time $1, .31$ to .66 at Time 2 , and .36 to .63 at Time 3. Factor loadings for regulation (5 items: impulsive, restless, inattentive, confused, obsessed) ranged from .45 to .62 at Time $1, .48$ to .70 at Time 2 , and .61 to .66 at Time 3. As shown in Table 1, the chi-square values were significant at all three time points; however, the other fit 
TABLE 1. Confirmatory Factor Analysis of Self-Regulation Scale by Time Point

\begin{tabular}{|c|c|c|c|c|c|c|}
\hline Measure & 1-factor model & $\begin{array}{c}\text { Between } \\
1-\text { and 2- } \\
\text { factor models }\end{array}$ & 2-factor model & $\begin{array}{c}\text { Between } \\
\text { 2- and 3- } \\
\text { factor models }\end{array}$ & 3-factor model & $\begin{array}{c}\text { Between } \\
1 \text { - and 3- } \\
\text { factor models }\end{array}$ \\
\hline & & \multirow[b]{2}{*}{$60.74(1)^{* * *}$} & Time $1(\mathrm{n}=838)$ & \multirow[b]{2}{*}{$5.04(2)$} & \multirow[b]{2}{*}{$\begin{array}{l}.97 \\
.97 \\
.96 \\
.05\end{array}$} & \multirow[b]{2}{*}{$65.78(3) * * *$} \\
\hline $\begin{array}{l}\chi^{2}(d f) \\
\chi^{2} \text { difference }(d f) \\
\text { GFI } \\
\text { CFI } \\
\text { NNFI } \\
\text { RMSEA }\end{array}$ & $\begin{array}{c}228.47(54) \\
\\
.96 \\
.95 \\
.94 \\
.06\end{array}$ & & $\begin{array}{c}167.73(53) \\
.97 \\
.97 \\
.96 \\
.05\end{array}$ & & & \\
\hline & & \multirow[b]{2}{*}{$111.91(1)^{* * *}$} & Time $2(\mathrm{n}=736)$ & & & \multirow[b]{2}{*}{$142.12(3) * * *$} \\
\hline $\begin{array}{l}\chi^{2}(d f) \\
\chi^{2} \text { difference }(d f) \\
\text { GFI } \\
\text { CFI } \\
\text { NNFI } \\
\text { RMSEA }\end{array}$ & $\begin{array}{c}399.74(54) \\
.92 \\
.93 \\
.92 \\
.09\end{array}$ & & $\begin{array}{c}287.83(53) \\
\\
.94 \\
.95 \\
.94 \\
.08\end{array}$ & $30.21(2) * * *$ & $\begin{array}{c}257.62(51) \\
.94 \\
.96 \\
.95 \\
.07\end{array}$ & \\
\hline
\end{tabular}


Time $3(\mathrm{n}=693)$

\begin{tabular}{|c|c|c|c|c|c|c|}
\hline $\begin{array}{l}\chi^{2}(d f) \\
\chi^{2} \text { difference }(d f)\end{array}$ & $414.62(54)$ & $84.39(1) * * *$ & $330.23(53)$ & $18.72(2) * * *$ & $311.51(51)$ & $103.11(3)^{* * *}$ \\
\hline GFI & .91 & & .93 & & .93 & \\
\hline CFI & .93 & & .95 & & .95 & \\
\hline NNFI & .91 & & .93 & & .93 & \\
\hline RMSEA & .10 & & .09 & & .09 & \\
\hline
\end{tabular}

Note . GFI $=$ Goodness of Fit Index CFI $=$ Comparative Fit Index; NNFI $=$ Non-Normed Fit Index; RMSEA = Root Mean Squared Error of Approximation.

$* p<.05 . * * p<.01 . * * * p<.001$. 
indexes suggested a good fit at all three time points (GFI, CFI, and NNFI > .93; $R M S E A<.09)$. Despite these results, factor intercorrelations were high at all three time points ( $r=.80$ at Time $1, r=.79$ at Time $2, r=.81$ at Time 3 ), suggesting that the two factors were not empirically distinct.

For the three-factor model, the chi-square values were significant at all three time points but the model fit well according to other indexes (GFI, CFI, and NNFI $>.93 ;$ RMSEA $<.10$; see Table 1). As shown in Figure 2, the factor loadings for the three-factor model were all significant $(p<.001)$, indicating convergent validity. Similar to the two-factor model, high intercorrelations emerged between the three factors at all three time points $(r s=.74$ to .95 at Time $1, .70$ to .86 at Time $2, .74$ to .91 at Time 3 ).

Next, comparisons of the different models were conducted at each time point. By fixing the correlation between the attention and activity regulation latent factors to 1.0, the three-factor model can be constrained to the two-factor model. Similarly, for the two-factor model, the correlation between the emotionality and regulation latent factors can be fixed to 1.0 to form the one-factor model. The

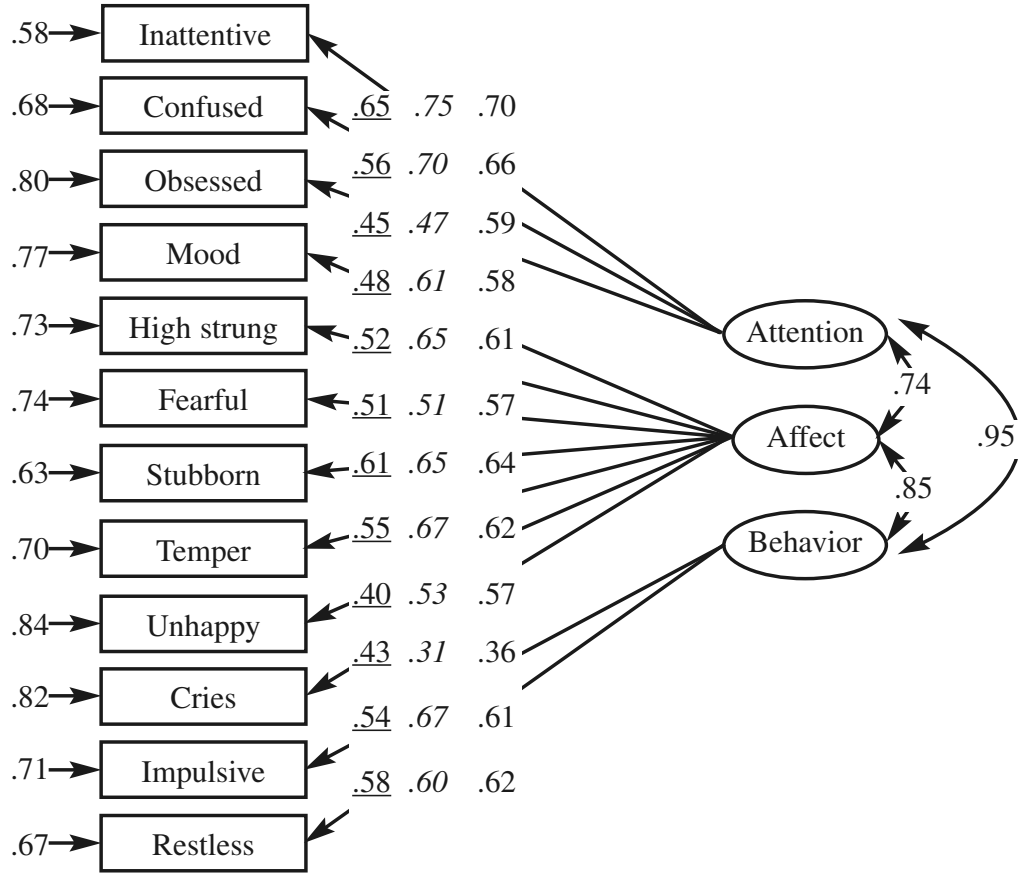

FIGURE 2. Confirmatory factor analysis results of 3-factor model of selfregulation. All coefficients are standardized. Errors variances of indicators and latent variable correlations are from 1986. 
TABLE 2. Means and Standard Deviations of Self-Regulation Scores

\begin{tabular}{llll} 
Time & Overall $(N=646)$ & Boys $(n=338)$ & Girls $(n=308)$ \\
\hline 1 & $2.49(.32)$ & $2.47(.34)$ & $2.52(.31)^{*}$ \\
2 & $2.55(.36)$ & $2.51(.36)$ & $2.59(.35)^{* *}$ \\
3 & $2.55(.36)$ & $2.52(.37)$ & $2.58(.34)^{*}$
\end{tabular}

Note. Gender differences within time point: $* p<.05 . * * p<.01$.

TABLE 3. Results of Repeated Measures Analysis of Variance for Self-Regulation Scale

\begin{tabular}{|c|c|c|c|c|}
\hline Source & $d f$ & $F$ & $\eta$ & $p$ \\
\hline \multicolumn{5}{|c|}{ Between subjects } \\
\hline Gender & 1 & $8.69 * *$ & .01 & .00 \\
\hline Error & 644 & $(0.23)$ & & \\
\hline \multicolumn{5}{|c|}{ Within subjects } \\
\hline Time & 2 & $9.88 * * *$ & .03 & .00 \\
\hline Time $\times$ Gender & 2 & 0.36 & .00 & .70 \\
\hline \multicolumn{5}{|c|}{ Within subjects contrasts } \\
\hline \multicolumn{5}{|l|}{ Time } \\
\hline Linear & 1 & $15.47 * * *$ & .02 & .00 \\
\hline Quadratic & 1 & 3.78 & .01 & .052 \\
\hline \multicolumn{5}{|l|}{ Time $\times$ Gender } \\
\hline Linear & 1 & 0.01 & .00 & .91 \\
\hline Quadratic & 1 & 0.72 & .00 & .40 \\
\hline \multicolumn{5}{|l|}{ Error } \\
\hline Linear & 644 & $(0.07)$ & & \\
\hline Quadratic & 644 & $(0.06)$ & & \\
\hline
\end{tabular}

Note. Values in parentheses represent mean square errors. $N=646$ (338 boys, 308 girls). $* p<.05 . * * p<.01 . * * * p<.001$.

three models thus were nested, allowing a direct comparison of the three solutions by means of chi-square difference tests (shown in Table 1). The only nonsignificant chi-square difference was between the two- and three-factor models at Time $1, \chi^{2}(2, N=838)=5.004, p>.05$. On the basis of these comparisons, 
the more differentiated models fit the data better. However, exploratory examination of subscales on the basis of the differentiated models revealed that the subscale reliabilities were low at all three time points. For example, the subscale reliabilities for the three-factor model were .71 to .77 for affect ( 7 items), .56 to .68 for attention ( 3 items), and .48 to .57 for behavior ( 2 items). Because these reliabilities were lower than the intercorrelations between the factors, which (as reported previously) exceeded .70 at all time points, it appears that the scales shared all of their reliable variance. Moreover, the high factor intercorrelations in the two- and three-factor models indicated considerable overlap. Thus, the weight of the evidence favored adoption of the more parsimonious one-factor solution.

As described in the analysis plan, to evaluate the findings regarding the factor structure of self-regulation, we replicated these analyses in another cohort of NLSY children who were born an average of 2 years after those in our primary sample. Children in the replication sample were assessed at the same ages and with the same measures as were those in our main sample. The pattern of findings was essentially identical, lending confidence to the results of the original CFA and model comparisons (details are available from the first author). Remaining analyses were conducted using only the main cohort.

We conducted two-group confirmatory factor analyses to examine whether there were gender differences in the structure of the self-regulation measure. Across the different models, when all parameters were constrained to be equal for boys and girls, all fit indexes (GFI, CFI, NNFI) indicated an acceptable fit (> $.90)$ indicating that the three models fit equally well for boys and girls at all three time points. Moreover, chi-square difference tests between the one-factor, twofactor, and three-factor models were not significant, indicating that the invariance across gender groups was sustained across the three models.

In summary, it appears that self-regulation is an integrated construct and that the measure works similarly for boys and girls. Although the overall pattern of results from analyses examining the factor structure of self-regulation suggested that the more differentiated models provided incrementally better fits to the data, the high intercorrelations between the various factors in the two- and three-factor models indicated that the different subcomponents of self-regulation were not empirically distinct. On the basis of these results, subsequent analyses focused on the global measure of self-regulation.

\section{Developmental Changes in Self-Regulation}

Age-related changes in self-regulation were examined in a repeated measures ANOVA with global self-regulation as the dependent variable, time point as a repeated factor, and gender as a between-groups factor (see Table 2 for the means and Table 3 for a summary of the ANOVA results). We included polynomial contrasts for linear and quadratic effects to examine developmental patterns. As hypothesized, there were significant main effects of time and gender. For time, the 
linear effect was significant; however, the quadratic effect was not. Follow-up dependent $t$ tests indicated that self-regulation increased significantly between Times 1 and $2, t(645)=-3.75, p<.001$, but not between Times 2 and $3, t(645)=$ -0.43 , ns. Gender also had a significant main effect on self-regulation-girls had higher levels of self-regulation than did boys (see Table 2 for means). The Gender $\times$ Time interaction was not significant, suggesting similar longitudinal patterns for boys and girls.

\section{Stability of Individual Differences in Self-Regulation}

The third research question concerned the stability of individual differences in self-regulation over time. There were significant correlations between self-regulation scores from Time 1 to Time $2(r=.49, p<.01)$ and from Time 2 to Time $3(r=.50, p<.01)$, with similar patterns emerging for boys (T1 to T2 $r=.49, \mathrm{~T} 2$ to $\mathrm{T} 3 r=.50, p \mathrm{~s}<.01$ ) and girls (T1 to T2 $r=.47$, T2 to T3 $r=.50, p \mathrm{~s}<.01$ ). The magnitude of the correlations across different ages showed little variation, and follow-up tests revealed no significant differences between coefficients across time period, either overall or within gender. These findings indicate that individual differences in self-regulation were fairly stable across the 8-year span from early childhood (when the sample was aged 4 to 5 years) to early adolescence (aged 12 to 13 years), contrary to our expectation that greater stability would be seen after middle childhood.

\section{Discussion}

In the present study, we examined the development of self-regulation in a longitudinal investigation of children who were assessed over an 8-year period. Results provided evidence of age-related increases in self-regulation, especially from early childhood to middle childhood, with girls exhibiting greater self-regulatory capacity than boys at all ages. We also found evidence of substantial stability in self-regulation, beginning in the preschool years. Finally, examination of the structure of self-regulation both overall and within gender suggested that selfregulation is an integrated construct. These findings contribute to the growing literature on self-regulation in several ways. Our study is one of only a few largescale longitudinal studies of self-regulation, and our results confirm and expand findings from previous research. Furthermore, by measuring self-regulation consistently over time in a long-term longitudinal sample, we provided novel information about developmental consistency and change in self-regulation.

We are among the first researchers to examine the multidimensional nature of self-regulation by empirically comparing three alternative conceptual models. Building on previous research, which has conceptualized self-regulation in different ways, we examined whether a one-, two-, or three-factor model best fit the data. On the basis of confirmatory factor analysis, the more differentiated models 
provided a slightly better fit to the data; however, in the two- and three-factor models, high intercorrelations emerged among the factors $(r \mathrm{~s}=.70$ to 95$)$, suggesting that they were tapping into highly related dimensions of self-regulation. We replicated these results in a second cohort of children and enhanced confidence in their robustness. The findings are consistent with previous reports of the interrelatedness of regulation and emotionality (e.g., Eisenberg et al., 1993, 1995; Lengua et al., 1998) and support the conceptualization of self-regulation as an interrelated set of capacities (Bronson, 2000; Committee on Integrating the Science of Early Childhood Development, 2000; Diaz \& Fruhauf, 1991; Zimmerman, 2000). Although we anticipated that the factor structure might differ with age, the results did not support this idea. Rather, the pattern of factor loadings at the three ages did not vary substantially, indicating that items related similarly to the overall construct at each time of measurement. Future researchers should replicate these analyses with a broader set of items, including additional indicators of attention and behavior as well as items that tap into other dimensions of self-regulation (e.g., goal-setting, planning). It also would be important to examine dimensions of selfregulation in younger children (e.g., infants). Although the present analyses appeared to support an integrated construct, it is possible that dimensions of selfregulation would be more readily separable in younger children, especially if the neural underpinnings of these dimensions mature at different times.

Theoretical models posit a growth in self-regulatory capacity from infancy into middle childhood (Bronson, 2000; Kopp, 1982). Despite the fact that levels of self-regulation were already high at the first time point (when children were 4 or 5 years old), a significant increase in overall levels of self-regulation occurred between early childhood and middle childhood. This finding is consistent with theory and previous research (e.g., Committee on Integrating the Science of Early Childhood Development, 2000; Gottfredson \& Hirschi, 1990; Grolnick \& Farkas, 2002). In contrast, we found little evidence for the notion that self-regulation continues to develop after middle childhood as related skills mature (Demetriou, 2000). Although the linear effect across all three time points was significant, follow-up tests indicated a significant increase in self-regulation only between early childhood (ages 4 to 5 years) and middle childhood (ages 8 to 9 years); the difference between middle childhood and early adolescence (ages 12 to 13 years) was not significant. Thus, the aspects of self-regulation measured in this study do not increase appreciably during late childhood, although we cannot rule out a future increase in middle adolescence to late adolescence. The present results also do not preclude the possibility that additional dimensions of self-regulation not studied here emerge or increase after middle childhood. Again, studies that include a broader array of assessments and examine additional dimensions of selfregulation are needed to address this possibility.

As hypothesized, girls exhibited higher self-regulatory ability than did boys. This finding supplements previous studies of related constructs in which similar gender differences were observed (e.g., Kochanska et al., 2000; Murphy et al., 1999; 
Stifter \& Spinrad, 2002). Furthermore, gender differences in favor of girls were found in all three age groups. Such enduring gender differences in self-regulatory ability may underlie frequently observed differences in theoretically related behaviors such as aggressiveness (Coie \& Dodge, 1998) and negative emotions such as anger and irritability (Rothbart \& Bates, 1998). However, we do not know the basis for this early and stable gender difference, which could reflect neurological underpinnings (differential maturation), temperamental differences in reactivity associated with gender, or differential socialization during the first few years. Further research is necessary. It is also possible that the aspects of self-regulation included in the measure were particularly characteristic of girls, and that different results might emerge if additional dimensions were assessed.

In line with our predictions, evidence of substantial stability in selfregulation emerged, with stability coefficients ranging from .47 to .50 . On the basis of the work by previous developmental researchers (e.g., Guerin \& Gottfried, 1994; Murphy et al., 1999), we had expected to see the stability of individual differences increase over time. This pattern did not emerge for global selfregulation scores; rather, the findings are consistent with research on related constructs, which has shown early emergence of stable individual differences in self-regulatory capacities. For example, researchers have found that individual differences in lack of control (Caspi et al., 1995), attentional control (Eisenberg et al., 1997), and ego control (Block, Block \& Keyes, 1988) assessed in the preschool years predict subsequent emotional and behavioral functioning, consistent with stable differences in self-regulatory abilities. Moreover, our findings are in line with estimates of trait consistency reported in Roberts and DelVecchio's (2000) meta-analysis of longitudinal studies of personality and temperament. These authors estimated cross-time correlations of .52 from 3.5 to 5.9 years of age, and .45 from 6 to 11.9 years of age, comparable to the cross-time correlations of .47 to .50 that we obtained in the present study. Future longitudinal research that examines influences on the development of multiple dimensions of self-regulation could clarify the developmental mechanisms underlying the observed stability in self-regulation (Diaz \& Fruhauf, 1991; Kochanska et al., 2000; Posner \& Rothbart, 2000).

The limitations of this study should be considered when interpreting the results. First, the self-regulation measure was based on a single reporter-the mother. Parental reports are widely used by childhood personality researchers and are considered a valid and reliable means of assessing child characteristics (Rothbart \& Bates, 1998). For example, parent ratings tend to be consistent with teacher ratings (e.g., Guerin \& Gottfried, 1994; Murphy et al., 1999). Nonetheless, reliance on a single reporter might have affected our results. For example, results of analyses examining the factor structure of self-regulation could reflect common method variance, which may have contributed to the high correlations between factors. Moreover, the observed stability of individual differences in selfregulation might in part reflect shared method variance. Future researchers should 
consider including multiple measures of self-regulation based on multiple reporters or multiple methods. Multimethod and multireporter studies may be especially important once children enter adolescence and parents have less opportunity to observe them throughout the day.

A second set of limitations stems from use of an archival dataset that was not originally designed to study self-regulation. Although there are a number of strengths in the NLSY that benefited the present analysis (including large sample size, availability of multiple cohorts, use of the same assessments across time points), the self-regulation measure was limited by the items available in the dataset. We tried to ensure that the selected items were comparable to those included in previous developmental research on similar constructs and to exclude markers of existing externalizing problems. However, the source measure (the BPI) was intended to assess behavior problems rather than normative aspects of self-regulation. The measurement context may have affected how mothers responded to the questionnaire and may have contributed to the high levels of self-regulation found in the present study. Future researchers should address normative aspects of self-regulation. The number of items included in the measure was also relatively small, providing a limited assessment of self-regulation, particularly when compared with the work of early childhood researchers who typically use a battery of measures to assess children's self-regulation (e.g., Calkins et al., 1998; Eisenberg et al., 1997; Kochanska et al., 2000; Murphy et al., 1999). Finally, although the BPI was designed for use with the age groups examined here, the items may have been less able to tap components of self-regulation that become salient at older ages, including long-term planning and goal-setting. This could help explain the lack of change in self-regulation from middle childhood to early adolescence.

Despite these caveats, the present study adds to the literature in developmental psychology by providing a large-scale, long-term examination of selfregulation from early childhood to adolescence. Self-regulation is now recognized as a critical aspect of functioning in multiple domains across the lifespan (Baumeister et al., 1998). Self-regulatory abilities have been linked to a variety of positive and negative outcomes, including academic success (Schunk \& Zimmerman, 1997), coping ability (Fabes \& Eisenberg, 1997), psychopathology (Cicchetti, 1996), sexual risk-taking behavior (Raffaelli \& Crockett, 2003), and addiction (Miller \& Brown, 1991). The growing attention to self-regulation as a central explanatory construct in child, adolescent, and adult functioning underscores the value of developmental research in this area.

\section{REFERENCES}

Abraham, C., \& Sheeran, P. (2000). Understanding and changing health behaviour: From health beliefs to self-regulation. In P. Norman, C. Abraham, \& M. Conner (Eds.), Understanding and changing health behaviour: From health beliefs to self-regulation (pp. 3-24). London: Routledge. 
Barkley, R. A. (1997). ADHD and the nature of self-control. New York: Guilford Press.

Baumeister, R. F., Leith, K. P., Muraven, M., \& Bratslavsky, E. (1998). Self-regulation as a key to success in life. In D. Pushkar, W. Bukowski, A. E. Schwartzman, D. M. Stack, \& D. R. White (Eds.), Improving competence across the lifespan: Building interventions based on theory and research (pp. 117-132). New York: Plenum.

Block, J., Block, J. H., \& Keyes, S. (1988). Longitudinally foretelling drug usage in adolescence: Early childhood personality and environmental precursors. Child Development, 59, 336-355.

Bronson, M. B. (2000). Self-regulation in early childhood: Nature and nurture. New York: Guilford Press.

Calkins, S. D., Smith, C. L., Gill, K. L., \& Johnson, M. C. (1998). Maternal interactive style across contexts: Relations to emotional, behavioral and physiological regulation during toddlerhood. Social Development, 7, 350-369.

Caspi, A., Henry, B., McGee, R. O., Moffitt, T. E., \& Silva, P. A. (1995). Temperamental origins of child and adolescent behavior problems: From age three to age fifteen. Child Development, 66, 55-68.

Cicchetti, D. (1996). Regulatory processes in development and psychopathology [Editorial]. Development and Psychopathology, 8, 1-2.

Coie, J. D., \& Dodge, K. A. (1998). Aggression and antisocial behavior. In N. Eisenberg (Vol. Ed.) \& W. Damon (Series Ed.), Handbook of child psychology, Vol. 3: Social, emotional, and personality development (pp. 779-862). New York: Wiley.

Committee on Integrating the Science of Early Childhood Development. (2000). From neurons to neighborhoods: The science of early childhood development. Washington, DC: National Academy Press.

Demetriou, A. (2000). Organization and development of self-understanding and self-regulation. In M. Zeidner (Ed.), Handbook of self-regulation (pp. 209-251). San Diego, CA: Academic.

Derryberry, D., \& Rothbart, M. K. (1988). Arousal, affect, and attention as components of temperament. Journal of Personality and Social Psychology, 55, 958-966.

Diamond, L. M., \& Aspinwall, L. G. (2003). Emotion regulation across the life span: An integrative perspective emphasizing self-regulation, positive affect, and dyadic processes. Motivation and Emotion, 27, 125-156.

Diaz, R. M., \& Fruhauf, A. G. (1991). The origins and development of self-regulation: A developmental model on the risk for addictive behaviours. In N. Heather, W. R. Miller, \& J. Greeley (Eds.), Self-control and the addictive behaviours (pp. 83-106). Botany, NSW, Australia: Maxwell Macmillan.

Eisenberg, N., Fabes, R. A., Bernzweig, J., Karbon, M., Poulin, R., \&. Hanish, L. (1993). The relations of emotionality and regulation to preschoolers' social skills and sociometric status. Child Development, 64, 1418-1438.

Eisenberg, N., Fabes, R. A., Murphy, B. C., Maszk, P., Smith, M., \& Karbon, M. (1995). The role of emotionality and regulation in children's social functioning: A longitudinal study. Child Development, 66, 1360-1384.

Eisenberg, N., Fabes, R. A, Shepard, S. A., Murphy, B. C., Guthrie, I. K., Jones, S., et al. (1997). Contemporaneous and longitudinal prediction of children's social functioning from regulation and emotionality. Child Development, 68, 642-664.

Eysenck, S. B. G., \& Eysenck, H. J. (1978). Impulsiveness and venturesomeness: Their position in a dimensional system of personality description. Psychological Reports, 43, $1247-1255$.

Fabes, R. A., \& Eisenberg, N. (1997). Regulatory control and adults' stress-related responses to daily life events. Journal of Personality and Social Psychology, 73, $1107-1117$. 
Feldman, S. S., \& Brown, N. L. (1993). Family influences on adolescent male sexuality: The mediational role of self-restraint. Social Development, 2, 15-35.

Fox, N. A., \& Calkins, S. D. (2003). The development of self-control of emotion: Intrinsic and extrinsic influences. Motivation and Emotion, 27, 7-26.

Gottfredson, M. R., \& Hirschi, T. (1990). A general theory of crime. Stanford, CA: Stanford University Press.

Graziano, W. G., \& Tobin, R. M. (2000, May). Regulation from infancy through adolescence. Presented at the Working Meeting of The Collaborative Center for Child WellBeing. Arlington, VA.

Green, L., Fry, A. F., \& Myerson, J. (1994). Discounting of delayed rewards: A life-span comparison. Psychological Science, 5, 33-36.

Grolnick, W. S., \& Farkas, M. (2002). Parenting and the development of children's selfregulation. In M. H. Bornstein (Ed.), Handbook of parenting, Vol. 5: Practical issues in parenting (pp. 89-110). Mahwah, NJ: Erlbaum.

Gross, J. J. (1999). Emotion regulation: Past, present, and future. Cognition \& Emotion, $13,551-573$.

Guerin, D. W., \& Gottfried, A. W. (1994). Developmental stability and change in parent reports of temperament: A ten-year longitudinal investigation from infancy through preadolescence. Merrill-Palmer Quarterly, 40, 334-355.

Hu, L., \& Bentler, P. M. (1995). Writing about structural equation models. In R. H. Hoyle (Ed.), Structural equation modeling: Concepts, issues, and applications (pp. 76-99). Thousand Oaks, CA: Sage.

Jöreskog, K., \& Sörbom, D. (1998). LISREL $8^{\circledR}$ : Structural Equation Modeling with the SIMPLIS ${ }^{T M}$ command language. Lincolnwood, IL: Scientific Software International.

Kelloway, E. K. (1998). Using LISREL for structural equation modeling. Thousand Oaks, CA: Sage.

Kline, R. B. (1998). Principles and practice of structural equation modeling. New York: Guilford Press.

Kochanska, G., Murray, K. T., \& Harlan, E. T. (2000). Effortful control in early childhood: Continuity and change, antecedents, and implications for social development. Developmental Psychology, 36, 220-232.

Kopp, C. B. (1982). Antecedents of self-regulation: A developmental perspective. Developmental Psychology, 18, 199-214.

Lengua, L. (2002). The contribution of emotionality and self-regulation to the understanding of children's response to multiple risk. Child Development, 73, 144-161.

Lengua, L., West, S. G., \& Sandler, I. N. (1998). Temperament as a predictor of symptomatology in children: Addressing contamination of measures. Child Development, 69, 164-181.

Maruyama, G. M. (1998). Basics of structural equation modeling. Thousand Oaks, CA: Sage.

Miller, W. R., \& Brown, J. M. (1991). Self-regulation as a conceptual basis for the prevention and treatment of addictive behaviours. In N. Heather, W. R. Miller, \& J. Greeley (Eds.), Self-control and the addictive behaviours (pp. 3-79). Botany, NSW, Australia: Maxwell Macmillan.

Mischel, W., Shoda, Y., \& Rodriguez, M. L. (1989). Delay of gratification in children. Science, 244, 933-938.

Murphy, B., Eisenberg, N., Fabes, R. A., Shepard, S., \& Guthrie, I. K. (1999). Consistency and change in children's emotionality and regulation: A longitudinal study. Merrill-Palmer Quarterly, 45, 413-444.

Peterson, J. L., \& Zill, N. (1986). Marital disruption, parent-child relationships, and behavioral problems in children. Journal of Marriage and the Family, 48, $295-307$. 
Posner, M. I., \& Rothbart, M. K. (2000). Developing mechanisms of self-regulation. Development \& Psychopathology, 12, 427-441.

Raffaelli, M., \& Crockett, L. J. (2003). Predicting sexual risk-taking: The role of selfregulation and attraction to risk. Developmental Psychology, 39, 1036-1046.

Roberts, A. W., \& DelVecchio, W. F. (2000). The rank-order consistency of personality traits from childhood to old age: A quantitative review of longitudinal studies. Psychological Bulletin, 126, 3-25.

Rothbart, M. K., \& Bates, J. E. (1998). Temperament. In N. Eisenberg (Vol. Ed.) \& W. Damon (Series Ed.), Handbook of child psychology, Vol. 3: Social, emotional, and personality development (pp. 105-176). New York: Wiley.

Schunk, D. H., \& Zimmerman, B. J. (1997). Social origins of self-regulatory competence. Educational Psychologist, 32, 195-208.

Stifter, C. A., \& Spinrad, T. L. (2002). The effect of excessive crying on the development of emotion regulation. Infancy, 3, 133-152.

Zagorsky, J. L., \& White, L. (1999). NLSY79 user's guide: A guide to the 1979-1998 National Longitudinal Survey of Youth data. Washington, DC: U.S. Department of Labor.

Zill, N. (1990). Behavioral Problems Index based on parent report (Publication No. 9103). Washington, DC: Child Trends.

Zimmerman, B. J. (2000). Attaining self-regulation: A social cognitive perspective. In M. Boekaerts, P. R. Pintrich, \& M. Zeidner (Eds.), Handbook of self-regulation (pp. 13-39). San Diego, CA: Academic.

\section{APPENDIX}

These are the items included in the self-regulation measure. The abbreviated labels used in the figures are included in square brackets. Items were scored so that higher scores indicated higher levels of regulation.

1. He/she has difficulty concentrating, cannot pay attention for long. [Inattentive]

2. $\mathrm{He} / \mathrm{she}$ is easily confused, seems to be in a fog. [Confused]

3. He/she has a lot of difficulty getting his/her mind off certain thoughts (has obsessions) [Obsessed]

4. He/she has sudden changes in mood or feeling. [Mood]

5. He/she is rather high strung, tense, and nervous. [High strung]

6. $\mathrm{He} / \mathrm{she}$ is too fearful or anxious. [Fearful]

7. He/she is stubborn, sullen, or irritable. [Stubborn]

8. He/she has a very strong temper and loses it easily. [Temper]

9. He/she is unhappy, sad, or depressed. [Unhappy]

10. $\mathrm{He} / \mathrm{she}$ cries too much. [Cries]

11. $\mathrm{He} / \mathrm{she}$ is impulsive, or acts without thinking. [Impulsive]

12. He/she is restless or overly active, cannot sit still. [Restless] 